\title{
The impact of HIV disease on an Irish prison population
}

\author{
M Murphy BSc MRCPI ${ }^{1}$, K Gaffney MB MRCPI, O Carey MB MICGP ${ }^{2}$, \\ E Dooley MB MRCPsych ${ }^{2}$ and $\mathbf{F}$ Mulcahy MD FRCPI ${ }^{1}$ \\ ${ }^{1}$ Department of Genitourinary Medicine, St James's Hospital, Dublin 8 and Irish Prison \\ Medical Service, Ireland
}

\begin{abstract}
Summary: Between January 1987 and January 1991, 168 known HIV-infected prisoners have been incarcerated in Dublin's Mountjoy prison. This figure constitutes $16.6 \%$ of the total HIVinfected population in the Republic of Ireland over the same period. One hundred and forty-one (84\%) of these prisoners have attended the Department of Genitourinary Medicine, St James's Hospital, Dublin. This group displayed considerable morbidity from HIV-related disease. Respiratory tract infection was the most frequent complication seen. Much additional morbidity was directly attributable to intravenous drug use. A survey of a representative group of inmates revealed that $64.7 \%$ were diagnosed HIV-positive in prison. The mean length of time spent incarcerated since the diagnosis of HIV infection was 38.9 months. Twenty-nine of 34 individuals who answered a questionnaire were imprisoned for drug-related crimes and 32 of 34 prisoners admitted to parenteral drug use within the prison. As the HIV epidemic unfolds in Dublin, increasing numbers of prisoners with symptomatic HIV disease will spend time incarcerated in Mountjoy prison. This will pose a considerable burden on prison and hospital medical services alike.
\end{abstract}

\section{Keywords: HIV disease, prison, intravenous drug use}

\section{Introduction}

HIV infection and AIDS has posed unprecedented problems for prison authorities worldwide. A survey performed on behalf of the Council of Europe found the prevalence of HIV infection, among prisoners in Western Europe unusually high in relation to the general population ${ }^{1}$. In Italy and Spain where mandatory screening of new inmates is practised, HIV prevalence rates of $16.8 \%$ and $26 \%$ respectively have been reported $^{1}$.

The first known HIV-infected prisoner in an Irish 'prison was identified in 1985. However, there is a paucity of information on the impact that HIV infection has had on the Irish prison service and, in particular, on the prison medical service. Prisoners known to be infected with HIV are held in Mountjoy prison, north Dublin, which is one of the country's largest closed correctional institutions. Since 1986 the prison has operated a segregation policy for male inmates who are identified as being HIV seropositive. Up to 42 prisoners are incarcerated in the separation unit. HIV-infected female prisoners (approximately 4 at any time) are

Correspondence to: Dr Maurice Murphy, Department of Genitourinary Medicine, Blundell Street, Leeds General Infirmary, Leeds LSI SEX, UK held in Mountjoy's women's prison, but are not segregated from other female prisoners.

As there is no compulsory screening for HIV, the prevalence of HIV infection in the general prison population of approximately 600 inmates is unknown. However, indirect evidence suggests that the actual number of HIV-infected prisoners in Mountjoy prison could be considerably greater than officially recognized. Up to $25 \%$ of offenders admitted to Mountjoy prison have a history of intravenous drug use ${ }^{2}$ and seroprevalence of HIV among Dublin's intravenous drug users has been estimated to be anything between $15 \%$ and $50 \%{ }^{3}$.

Since January 1987 the medical care of HIVinfected inmates in Mountjoy prison has been coordinated between the prison medical service and the Department of Genitourinary Medicine at St James's Hospital. Prisoners regularly attend the outpatient HIV clinic for clinical assessment and monitoring of their HIV disease. Direct admission to hospital for HIVrelated illness is arranged, when necessary, between the prison medical service and the genitourinary medical team. Most prisoners continue to attend for monitoring of their HIV disease on release from prison. The aim of this study was to examine in detail the demographic, clinical and custodial profiles of a cohort of HIV infected 
individuals who have been incarcerated in Mountjoy prison over a 4-year period.

\section{SUBJECTS AND METHODS}

All known HIV seropositive prisoners incarcerated in Mountjoy prison between January 1987 and January 1991 were identified from prison medical records. These were cross-referenced with the medical register at the Department of Genitourinary Medicine, St James's Hospital. Case notes were reviewed for demographic information, risk factor for $\mathrm{H} 1 \mathrm{~V}$ acquisition, and current clinical staging of H1V disease ${ }^{4}$. To assess the pattern of HIV-related disease and morbidity, both as inmates and when released, case notes were reviewed for clinical episodes requiring evaluation, treatment, admission to hospital or specialist referral. Particular note was made of other communicable diseases including hepatitis B, pulmonary tuberculosis and sexually transmitted diseases (STDs). The cause of death, if known, was documented.

To obtain a profile of custodial care, and to establish the pattern of injecting drug practices among HIV-infected prisoners in the segregation unit, a voluntary and confidential structured interview/questionnaire, was carried out on inmates over a 2-week period in January 1991. The reason(s) for imprisonment, current sentence, the number of prison terms, year and place of diagnosis of H1V infection and total length of time incarcerated in the segregation unit since, diagnosis of H1V infection were documented. Inmates were questioned for details of intravenous drug use, including age of commencement, and whether they had injected drugs within the prison.

\section{RESULTS}

\section{Demographic}

Over the 4-year period between January 1987 and January 1991, 168 (157 male, 11 female) known HIVpositive prisoners have been incarcerated in Mountjoy prison. Of these, 141 (83.9\%; 134 male, 7 female) have attended the Department of Genitourinary Medicine in St James's Hospital for management of their H1V disease. The mean age of this group was 28.8 years (range 19-43). Intravenous drug use was the predominant risk factor identified for the acquisition of H1V (138/141, 97.8\%).

\section{Clinical}

Of the 141 current or ex-prisoners who attended $5 \mathrm{t}$ James's Hospital, 58 (41.1\%) were classified as CDC group It, 54 (38.3\%) as CDC group III and 29 (20.6\%) CDC group IV H1V disease. Figure 1 summarizes the major diagnostic categories of clinical problems (total 229) identified in this population over the 4-year period. Pulmonary, gastrointestinal, and dermatological conditions constituted the commonest

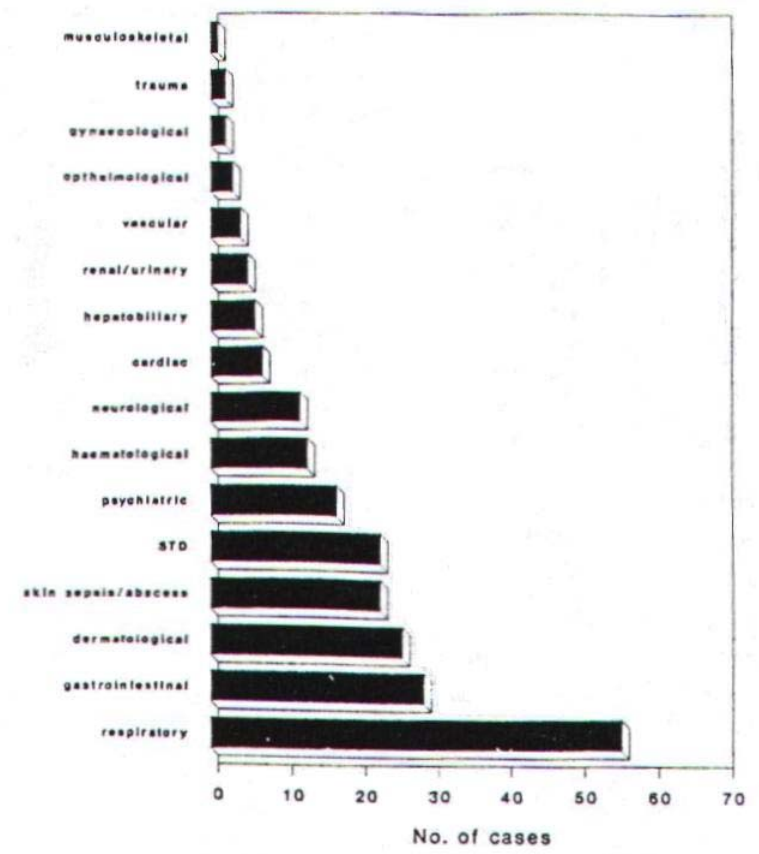

Figure 1. Frequency distribution showing major diagnostic categories of clinical conditions (total 229) identified in study population $(n=141)$

clinical problem documented. Bacterial lower respiratory tract infection was the single most common condition seen. More detailed analysis of these 229 clinical episodes revealed that considerable morbidity was directly attributable to intravenous drug use (skin sepsis/abscess 22, hepatitis 6, peripheral arterial occlusion 2 and femoral vein thrombosis 2, drug overdose 2, bacterial endocarditis 2, and one case of Fournier's gangrene of scrotum). Mycobacterium tuberculosis infection was identified in 6 individuals (pulmonary in 3 and extrapulmonary in 3 ). There was evidence of previous exposure to hepatitis B in 92 $(65.2 \%)$ individuals. Eighty-six $(60.9 \%)$ had antiheptitis B core IgG ab and $6(4.25 \%)$ were HBs $\mathrm{Ag}$ and/or $\mathrm{HBe} \mathrm{Ag}$ positive. In $13(9.2 \%)$ individuals serological markers for hepatitis B were negative and the remaining $29(20.6 \%)$ were untested. Sexually transmitted infections were identified in 20 individuals of whom 17 had genital warts.

There were 14 direct admissions from prison to St James's Hospital for HIV-related problems. Six had CDC stage IV disease. Bacterial lower respiratory tract infection was the commonest reason for admission (4/14). Two inmates were admitted with Pneumocystis carinii pneumonia (PCP), one of whom was from the main prison block, and was only subsequently diagnosed H1V seropositive on admission to hospital.

A total of 12 deaths occurred in the study population. Five of the 12 had early H1V disease (CDC stage II/III). Three of the deaths occurred whilst in custody; one each from suicide, drug overdose and PCP. One died shortly following 
Table 1. Custodial profile of a group of male inmates $(n=34)$ in the segregation unit of Mountjoy prison

\begin{tabular}{llll}
\hline & Mean & Median & Range \\
\hline Age (years) & 28.2 & 27.5 & $21-40$ \\
$\begin{array}{l}\text { Current sentence (months) } \\
\begin{array}{l}\text { Current sentence served } \\
\text { (months) }\end{array}\end{array}$ & 21.3 & 11 & $1-144$ \\
$\begin{array}{l}\text { Number of prison terms } \\
\quad \text { January 1986 to January 1991 }\end{array}$ & 3 & - & $1-8$ \\
$\begin{array}{l}\text { Total length incarcerated } \\
\text { January 1986 to January 1991 } \\
\text { (months) }\end{array}$ & 38.9 & 38 & $6-60$ \\
& & &
\end{tabular}

compassionate release to hospital for treatment of Fournier's gangrene.

\section{Custodial}

Thirty-four out of a group of 38 prisoners in the segregation unit completed the questionnaire/ interview on details of their custody and sentencing. Two were remand prisoners. Table 1 outlines the custodial details of this group. Twenty-nine (85.2\%) were imprisoned for drug-related crimes. All but two had used drugs intravenously prior to current term of imprisonment. Two inmates claimed to have commenced injecting drug use during current sentence and one other inmate had commenced using intravenous drugs during a previous term of imprisonment. Thirty-two (94\%) admitted to continued intravenous drug use within the prison. The mean length of time of diagnosis of HIV infection was 3.7 years (range 6 months to 5 years) and $22(64.7 \%)$ had been HIV-positive for more than 4 years. Twenty-two $(64.7 \%)$ had been diagnosed HIV seropositive within the Irish prison system. The distribution of the clinical staging of HIV disease in this subgroup of inmates was similar to that of the study population as a whole; $22(64.7 \%)$ were clinically classified as CDC group II disease, 11 (32.3\%) CDC group III disease and 5 (14.7\%) group IV disease.

\section{DISCUSSION}

Although the WHO's special programme on AIDS has laid down policy guidelines for the management of HIV-infected prisoners ${ }^{5}$, there is no clear consensus of approach. Several studies have addressed the issues of prevalence and transmission of HIV within prison institutions ${ }^{6-10}$. However, few studies have detailed the actual or potential clinical burden of HIV disease, with perhaps the exception of tuberculosis ${ }^{11,12}$, on prison and allied medical services. We have attempted to detail the pattern of clinical disease and custodial profile of a cohort of HIV-infected prisoners (ex and current) in Ireland.

Between January 1987 and January 1991, 168 known HIV-infected prisoners were incarcerated in Mountjoy prison. This figure represents an astonishing $16.6 \%$, of the total number of cases of HIV infection reported in the Republic of Ireland over the same period ${ }^{13}$. Although the study population comprised both current and ex-inmates, evidence suggests that the spectrum of clinical conditions seen are a valid representation of those that occur in any given group of HIV-infected inmates held in custody in Mountjoy prison. Firstly, the distribution of clinical staging of HIV disease in the subgroup of inmates studied were similar to that of the whole population. Secondly, as is seen from their custodial pattern, many prisoners are reoffenders, and frequently alternate between periods of imprisonment and release.

Although $20.6 \%$ of the study population were clinically classified as having symptomatic HIV disease (CDC stage IV) at the end of the study period, there appeared to be a disproportionate level of morbidity among the group as a whole. The pattern of HIV disease is similar to that previously reported in an Irish population ${ }^{14}$. Respiratory tract infection, particularly bacterial, was the commonest clinical problem identified. However, despite reports of an increased frequency of pulmonary tuberculosis in HIV-infected prison inmates ${ }^{11,12}$, it was diagnosed in only 3 individuals in this study, none of whom was in custody at the time of diagnosis.

There was considerable morbidity related to intravenous drug use. The large number of cases of skin sepsis and abscess formation due to the use of contaminated needles were not only seen in ex-inmates but also in prisoners in custody. This would suggest that significant parenteral drug misuse occurs within Mountjoy prison, a suspicion supported by the findings of the survey of inmates. Several studies have already highlighted the extent of drug misuse and needle sharing in prisons worldwide ${ }^{6-8,15}$. All but two prisoners in our survey had a history of injecting illicit drugs prior to their current term of imprisonment. The inference from this data is that these two individuals probably became infected with HIV through needle sharing following incarceration. Ninety-four per cent of those surveyed in this study continued to inject drugs whilst in prison. Assuming that the pattern of drug use is not dissimilar among intravenous drug users in the main prison body, there is considerable potential for transmission of HIV, particularly as inmates are unlikely to have exclusive access to their own injecting equipment.

Not surprisingly psychiatric morbidity, e.g. depression, was common in the study population. There are a wide variety of psychiatric conditions recognized in individuals with HIV infection and AIDS $^{16}$, many of which are likely to be exacerbated by incarceration in prison. Three of the 12 deaths were as a result of suicide and/or drug overdose and two of these occurred in custody. Psychiatric illness among inmates is a major determinant of prison suicide ${ }^{17}$. In addition to adequate medical facilities and services, there is a need for ready access to 
comprehensive psychiatric and counselling services which may play an important role in attempts to reduce rates of prison suicides ${ }^{18}$.

No information was sought on prisoners' sexual practices either within or outside prison. Other studies have highlighted sexual risk behaviour and potential for sexual transmission of HIV in prisons ${ }^{6,9}$. However, the high prevalence of sexually-acquired infections in this group is a source of concern. It lends support to reports that intravenous drug users in Dublin are failing to adopt safe sex practices ${ }^{19}$. The potential risk of transmission of HIV to partners in the community once released from prison deserves recognition.

More detailed study of custodial patterns of $\mathrm{HIV}$-infected inmates revealed that many have spent considerable periods in custody. Of those prisoners surveyed/ the mean total length of time (38.9 months) spent in custody over the 5-year period since the establishment of the segregation unit in Mountjoy, was considerably greater than that of a population of intravenous drug users who had served custodial sentences in a London prison ${ }^{7}$. Significantly, most were re-offenders with a mean number of prison terms of 3 . The reasons for this are varied. Existing drug treatment services are inadequate to deal with Dublin's large population of intravenous drug users, estimated to be around $7000^{3}$, necessitating continued involvement in crime to support their addiction. Moreover, illicit intravenous drug use in Ireland is concentrated mainly in Dublin and active users are unlikely to move outside this jurisdiction. It is not surprising, therefore, that $65 \%$ of those inmates surveyed had been HIV seropositive for greater than 4 years. Assuming that this pattern continues, one can expect an increasing burden on the prison medical services from inmates with symptomatic and advanced HIV disease.

This study has highlighted a number of important points relating to the burden of HIV disease on an Irish prison population. A substantial proportion of Ireland's total HIV-infected population have spent time in custody in Mountjoy prison. Given the prevalence of HIV infection among Dublin's drug users and the number of offenders that use intravenous drugs, the true prevalence of HIV infection among inmates is probably greater than officially recognized. Much of the morbidity, and indeed mortality, of this population was drug related. As the HIV epidemic among Dublin's drug users progresses, and considering their custodial pattern, increasing numbers of HIV-infected prisoners with symptomatic and advanced HIV disease will be incarcerated. This will further stretch a prison medical service already ill-equipped to deal with a problem of this scale. It is clear that considerable medical and financial resources need to be devoted to the management of HIV disease in Irish prisons.

Acknowledgements: We thank Mountjoy Prison Administration and the Irish Department of Justice for their assistance.

\section{References}

1 Harding TW. AIDS in prison. Lancet 1987;ii:1260-3

2 O'Mahony P. Abstinence in treated and untreated opiate abusers: a study of a prison sample. Ir J Psychol Med 1990;7:121-3

3 O'Kelly F, Bury G, Carey O. Policy statement on illicit drug use and problems of drug addiction. Ir Coll Gen Pract 1989

4 Centre for Disease Control. Revision of the CDC surveillance case definition fur acquired immune deficiency syndrome. $M M W R$ 1987;36(suppl 1s):3s-15s

5 WHO consultation on prevention and control of AIDS in prisons. Lancet 1987; ii: 1263-4

6 Carvell ALM, Hart GJ. Risk behaviours for HIV infection among drug users in prison. $B M J$ 1990:300:1383-4

7 Dye $\mathrm{S}$, Isaacs $\mathrm{C}$. Intravenous drug misuse among prison inmates: implications for spread of HIV. BMJ 1991;302:1506

8 Gaughwin MD, Douglas RM, Liew C, et al. HIV prevalence and risk behaviours for HIV transmission in South Australian prisons. AIDS 1991; 5:845-51

9 Power KG, Markova I, Rowlands A, et al. Sexual behaviour in Scottish prisons. BMJ 1991; 302:1507-8

10 Brewer TF, Vlahov D, Taylor E, et al. Transmission of HIV-1 within a statewide prison system. AIDS 1988;ii:363-7

11 Darbyshire JH. Tuberculosis in prisons. BMJ 1989;299:874

12 Snider DE, Hutton MD. Tuberculosis in correctional institutions. JAMA 1989:261:436-7

13 Department of Health AIDS statistics, Dublin, January 1991

14 Murphy M, Misquito N, Pomeroy L, et at. Admissions for HIV related disease in a Dublin hospital 1987-1990. Int J STD AIDS 1991;2:436-9

15 Kennedy DH, Nair G, Elliot L, Ditton J. Drug misuse and sharing of needles in Scottish prisons. BMJ 1991;302:1507

16 Maj M- Psychiatric aspects of HIV-1 infection and AIDS. Psychol Med 1990; 20:547-63

17 Dooley E. Prison suicide in England and Wales, 197287. Br J Psychiatry 1990; 156:40-5

18 Skegg K, Cox B. Impact of psychiatric services on prison suicide. Lancet 1991:338:1436-8

19 Pomeroy L, O'Connor J, Joseph B. Needle sharing and sexual behaviour amongst attenders at a methadone maintenance programme in Dublin. VII International Conference on AIDS, Florence, June 1991 (abstract)

(Accepted 13 August 1992) 